\title{
Survey and Management Outcome of Neonatal Jaundice from a Developing Tertiary Health Centre, Southern Nigeria.
}

\author{
${ }^{1}$ Dakoru Edoghotu Omekwe, ${ }^{2}$ Mukoro Duke George , ${ }^{1}$ Briseimo T. \\ Kennis, ${ }^{1}$ Benson Nana Fakuma, Chilunum Chioma Evidence, ${ }^{1}$ Ebitimi Fiyebobra \\ Destiny, ${ }^{1}$ Fawei Erepamo Seimiekumo, ${ }^{1}$ Gani I.O. Owoeye \\ ${ }^{1}$.Department of community Medicine, Niger-Delta University Teaching Hospital. \\ ${ }^{2}$.Department of Accident and Emergency Medicine, Niger-Delta University Teaching Hospital, Okolobiri, \\ Yenagoa, Bayelsa, Nigeria.
}

\begin{abstract}
:
Background information: Neonatal jaundice is a very common condition worldwide, occurring in up to $60 \%$ of term and $80 \%$ of preterm new born in the first week of life. The incidence, aetiological and contributory factors to neonatal jaundice differs in ethnicity and geographical distribution. In Nigeria, it accounts for between 23\% and $60 \%$ of admission into the Special Care Baby Unit (SCBU), and various factors are responsible for its occurrence. The aim of the study was to assess the frequency, determinants, prevalence and predictors of Neonatal jaundice among in-born neonates and out-born neonates managed in Niger Delta University Teaching Hospital(NDUTH), Okolobiri, Bayelsa State

Material and Method: A retrospective descriptive study of Case file of all in-born and out-born neonates admitted in Special Care for neonatal jaundice from January 2010 to December, 2012 were included. Information from case file of the index cases were collected using a proforma of data collection sheet within a ten week period. Socio-demographic characteristics, associated risk factors, prevalence rate for each year, survival rate, treatment modalities and out-come were determined. The data was organized, validated, and analysed using SPSS. Quantitative variables were summarized using range, mean, and standard deviation. Categorical variables were tabulated using frequencies and percentages. Chi-square test were used for testing the significance of association between categorical variables. Student's t-test was used to compare two means. Survival rate of treatment modalities determined.

Result: A total of 664 neonates were admitted into the special care baby unit of the Pediatrics department, NDUTH. 199 (17.9\%) of the neonates were diagnosed with neonatal jaundice(NNJ). Majority of which were aged between 1-2 days making about 82 (41.2\%) of the neonates with NNJ.The males, were most commonly affected $121(60.8 \%)$ compared to females 78 (39.2\%). Maternal age with the highest cases of children with NNJ was between 26-30 years, 59 (29.6\%). Majority of the women had secondary level of education, 121 (60.8\%).The prevalence rate were 240, 227), 300 per 1000 neonates admitted in the hospital for 2010.2011 and 2012 respectively. The identifiable risk factors in this study were preterm's 81(40.7\%), low birth weights 105(52.8\%), poor maternal booking status, neonatal sepsis 119(59.8\%) and birth asphyxia (low APGAR score).The use of more than one treatment modality improve survival rate of neonates with Jaundice. Phototherapy is the most important option that must be used in the management of Neonatal Jaundice.

Conclusion: Neonatal jaundice remains high among cases admitted into the special care baby unit in developing nations. Therefore antenatal and neonatal care should be improved and supported by all health care stakeholders if childhood millennium development goals would be achieved.
\end{abstract}

Keywords: Neonatal Jaundice, Phototherapy, neonatal sepsis.

\section{Introduction:}

Neonatal jaundice is a very common condition worldwide, occurring in up to $60 \%$ of term and $80 \%$ of preterm new born in the first week of life ${ }^{[1,2]}$. Extreme hyperbilirubinaemia is uncommon in developed countries. It is still a common cause of neonatal morbidity and mortality in developing countries often resulting in kernicterus with its resultant burden, such as medical, economic and social, on the patient family and society at large ${ }^{3}$.

The incidence, aetiological and contributory factors to neonatal jaundice differs in ethnicity and geographical distribution. In developed countries feto-maternal blood group incompatibilities are the leading cause of neonatal jaundice, but in developing countries, the case is different as it is mostly prematurity, G6PD Deficiency, infective causes as well as effects of herbal medications in pregnancy, application of dusting powder on baby, use of camphor balls to store baby's clothe that mainly constitute the aetiology in developing countries $^{4}$. Severe neonatal jaundice can therefore be said to have modifiable risk factor particularly in 
developing countries ${ }^{5}$.Two types of neonatal jaundice exist, they are conjugated and unconjugated. The unconjugated is further divided into; physiologic and pathologic .

PHYSIOLOGICAL JAUNDICE: This usually appears about the $2^{\text {nd }}$ or $3^{\text {rd }}$ day of life, peaks at about $5^{\text {th }}$ day and disappears within 10 days 10 . The serum bilirubin levels are usually <12mg/dl (204umol/l). The baby is said to be otherwise well. It is a diagnosis of exclusion ${ }^{6}$.The causes include relative high red cell mass and hence increased bilirubin load to the liver. reduced red cell life span, increased release of haem from infective erythropoesis, reduced hepatic uptake due to low ligandin concentration,increased enterohepatic circulation.

PATHOLOGICAL JAUNDICE; this occurs in unwell babies. It is jaundice in the first $24 \mathrm{hr}$ of life. The total serum bilirubin level $>12 \mathrm{mg} / \mathrm{dl}(204 \mathrm{umol} / \mathrm{l})$ in term or $>5 \mathrm{mg} / \mathrm{dl}(85 \mathrm{umol} / \mathrm{l}) / \mathrm{day}$. It is also characterised by conjugated bilirubin $>2 \mathrm{mg} / \mathrm{dl}$ (34umol/l), clinical jaundice lasting $>2$ weeks, with evidence of haemolysis.Common causes of pathologic unconjugated hyperbilirubinaemia in Nigeria are ABO Incompatibility, G6PD deficiency, infections, and prematurity ${ }^{6}$. Studies have also shown that increased haemolysis due to rhesus incompatibility, pyruvate kinase deficiencies, membranopathies, hemolytic agents (such as naphthalene balls, dusting powder), liver cell membrane defects ${ }^{6}$.

The risk factors for pathological jaundice are; previous sibling with neonatal jaundice, maternal diabetes, maternal drugs (such as oxytocin, diazepam, promethazine), prematurity, and low birth weight male sex, ethnicity, geographical location ${ }^{6}$.

It is a known fact that neonatal jaundice is a common problem worldwide. In Nigeria, it accounts for between $23 \%$ and $60 \%$ of admission into the Special Care Baby Unit (SCBU), and that various factors are responsible for its occurrence. What percentage of neonatal admission does neonatal jaundice constitute in NDUTH ?,What is the leading cause, or contributory factor of neonatal jaundice in NDUTH? The aim of the study was to assess the frequency and determinants in neonates who had neonatal jaundice in NDUTH over a 3 year period, the Prevalence and Predictors of Neonatal jaundice among in-born neonates and out-born neonates managed in Niger Delta University Teaching Hospital(NDUTH), Okolobiri, Bayelsa State. Investigate the adverse sequelae, treatment, and risk factors arising from parents/care givers as well as babies with jaundice.

\section{Materials And Methods}

A retrospective descriptive study of Case file of all inborn and out born neonates admitted in Special Care for neonatal jaundice from January 2010 to December, 2012 were included. Those included in the study must not be greater than 28days, and have been admitted in the SCBU, while patient age greater than 28 days or not admitted in SCBU were excluded.

Information from case file of the index cases were collected using a proforma of data collection sheet within a ten week period. The data was organized, validated, and analysed using SPSS. Quantitative variables were summarized using range, mean, and standard deviation. Categorical variables were tabulated using frequencies and percentages. Chi-square test were used for testing the significance of association between categorical variables. Student's t- test was used to compare two means.

ETHICAL CONSIDERATION: Approval was obtained from the ethical committee of the college of health sciences, Niger-Delta University.

\section{Limitation Of Study}

The retrospective study did not afford us the opportunity to actively enquire for the application of dusting powder, as well as lack of facility for assay of the G6PD status of the subject denied the investigators of the opportunity to highlight these know predisposing factor as their aetiology. Furthermore,poor clerking of the patients for possible risk factors was a major contributing factor as to why some predisposing factors such as ABO Incompatibility were not highlighted. In addition we had difficulty in accessing case notes from the record department, as well as inability to locate and follow up documentation on the discharge subjects to ascertain if they were long term sequelae.

Conflict of Interest : none to declare

\section{Results}

A total of 664 neonates were admitted into the special care baby unit of the Pediatrics department, NDUTH during the period of this review, out of which $199(17.9 \%)$ of the neonates were diagnosed with neonatal jaundice(NNJ). Majority of which were aged between 1-2 days making about 82 (41.2\%) of the neonates admitted for NNJ.There were more cases of NNJ in the males, $121(60.8 \%)$ compared to females 78 (39.2\%). Maternal age with the highest cases of children with NNJ was between 26-30 years, $59(29.6 \%)$, as well as majority of the women had secondary level of education, $121(60.8 \%)$. 
Table1: Socio-demographic characteristics of the patients

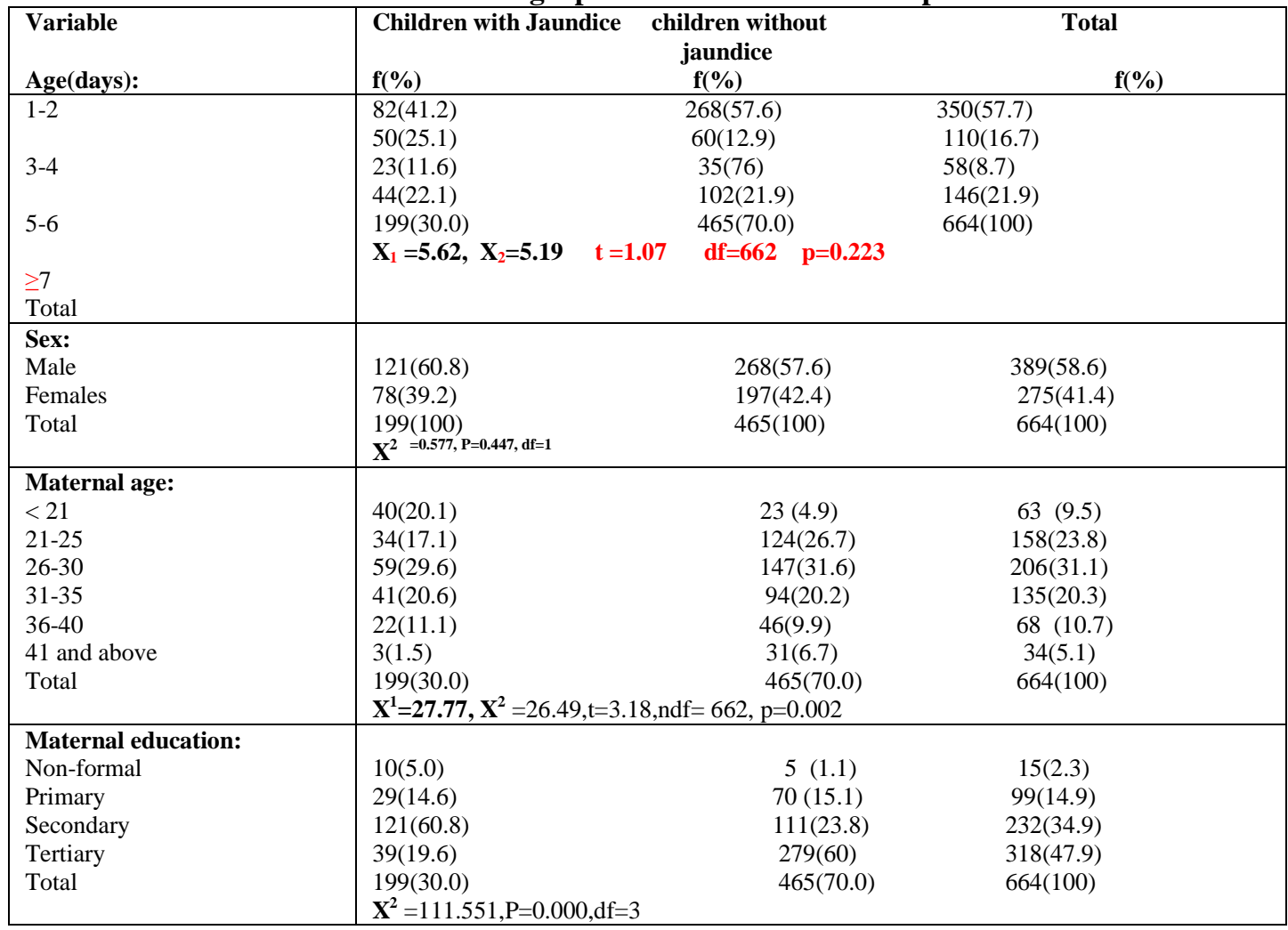

Table 2 shows the yearly prevalence of NNJ in NDUTH, in the years under review (2010- 2012) were; 2010 (240), 2011 (227), 2012 (300) per 1000 neonates admitted in the hospital, making a total of all neonatal admissions in SCBU throughout this period. The highest cases of admission in SCBU on account of NNJ were seen in 2012.

Table 2: Prevalence of Neonatal Jaundice

\begin{tabular}{|l|ccc|c|}
\hline Year & \multicolumn{2}{|l|}{ Children with NNJ } & Children without NNJ & Total \\
& F (\%) & prevalence Rate(1000) & f $(\%)$ \\
\hline 2010 & $38(19.1)$ & 240 & $120(25.8)$ & $158(23.8)$ \\
2011 & $56(28.1)$ & 227 & $191(41.1)$ & $247(37.2)$ \\
2012 & $105(52.8)$ & 405 & $154(33.1)$ & $259(39.0)$ \\
Total f (\%) & $199(30.0)$ & 300 & $465(70.0)$ & $664(100)$ \\
$\mathbf{X}^{\mathbf{2}=}$ & $\mathbf{X}^{\mathbf{2}=\mathbf{2 . 6 9 4}} \mathbf{d f = 2} \mathbf{p = 0 . 0 0 0}$ & & \\
\hline
\end{tabular}

Table 3 showed the association between identifiable risk factors and the occurrence of NNJ. The identifiable risk factors in this study were gestational age, birth weights, maternal booking status, neonatal sepsis and APGAR score.The occurrence of NNJ was more in the preterm's 81(40.7\%), low birth weights $105(52.8 \%)$, Neonatal sepsis 119(59.8) and low APGAR score. However, low occurrence of NNJ occurred in breastfed neonates and history of naphthalene use.

Table 3:Analysis of association between identifiable risk factors and the occurrence of NNJ

\begin{tabular}{|c|c|c|c|}
\hline Gestational age & Neonate with Jaundice & Neonatal without Jaundice & Total \\
\hline Preterm & $81(40.7)$ & $101(21.7)$ & $182(27.4)$ \\
\hline Term & $113(56.8)$ & $334(71.8)$ & $447(67.3)$ \\
\hline Post-date & $5(2.5)$ & $30(6.5)$ & $35(5.3)$ \\
\hline $\begin{array}{l}\text { Total } \\
\mathrm{X}^{2}=27.109 \quad \mathrm{df}=2\end{array}$ & $\mathrm{p}=0.000^{199(30)}$ & $465(70)$ & $664(100)$ \\
\hline \multicolumn{4}{|l|}{ Birth Weight } \\
\hline Low Birth Weight & $105(52.8)$ & $143(30.8)$ & $248(37.3)$ \\
\hline Normal & $83(41.7)$ & $252(54.2)$ & $335(50.5)$ \\
\hline Macrosomia & $11(5.5)$ & $70(15.0)$ & $81(12.2)$ \\
\hline Total & $199(30)$ & $465(70)$ & $664(100)$ \\
\hline \multicolumn{4}{|c|}{$X^{1}=2.6487, \quad X^{2}=3.1298, d f=662, p=0.000, t=5.85$} \\
\hline Booking Status & Jaundiced & Non Jaundiced & Total \\
\hline Booked & $154(77.4)$ & $250(53.8)$ & $404(60.8)$ \\
\hline
\end{tabular}




\begin{tabular}{|c|c|c|c|}
\hline Unbooked & $45(22.6)$ & $215(46.2)$ & $260(39.2)$ \\
\hline Total & $199(30)$ & $465(70)$ & $664(100)$ \\
\hline \multirow{2}{*}{\multicolumn{4}{|c|}{$\begin{array}{l}X^{2}=32.644, d f=1, p=0.000 \\
\text { Neonatal Sepsis }\end{array}$}} \\
\hline & & & \\
\hline Present & 119(59.8) & $52(11.2)$ & $171(25.8)$ \\
\hline Absent & $80(40.2)$ & $413(88.8)$ & $493(74.2)$ \\
\hline Total & 199(30.0) & $465(70.0)$ & $664(100)$ \\
\hline \multicolumn{4}{|c|}{$\mathrm{X}^{2}=172.263 \mathrm{df}=1, \mathrm{p}=0.000$} \\
\hline \multicolumn{4}{|l|}{ Apgar Score } \\
\hline Good & $16(8.0)$ & $228(49.0)$ & 244(36.7) \\
\hline Mild & $49(24.6)$ & $145(31.2)$ & 194(29.2) \\
\hline Moderate & $57(28.7)$ & $52(11.2)$ & $109(16.4)$ \\
\hline Severe & $77(38.7)$ & $40(8.6)$ & $117(16.7)$ \\
\hline Total & 199(30.0) & $465(70.0)$ & $664(100)$ \\
\hline \multicolumn{4}{|c|}{$X^{2}=163.275, d f=3, p=0.000$} \\
\hline \multicolumn{4}{|c|}{ Breastfeeding } \\
\hline EBF & $80(40.2)$ & $250(53.8)$ & $330(49.7)$ \\
\hline Mixed & $38(19.1)$ & $65(14.0)$ & 103(19.6) \\
\hline Not Breastfed & $81(40.7)$ & $150(32.2)$ & 231(34.7) \\
\hline Total & 199(30.0) & $465(70.0)$ & $664(100.0)$ \\
\hline \multicolumn{4}{|c|}{$\mathrm{X}^{2}=10.367, \mathrm{df}=2.0, \mathrm{P}=0.006$} \\
\hline \multicolumn{4}{|c|}{ History of Naphthalene use } \\
\hline Positive Use & $5(2.5)$ & $20(4.3)$ & $25(3.8)$ \\
\hline Nil & 194(97.5) & $445(95.7)$ & $639(96.2)$ \\
\hline Total & 199(30.0) & $465(70.0)$ & $664(100)$ \\
\hline $\mathrm{X}^{2}=1.230, \mathrm{df}=$ & 267 & & \\
\hline
\end{tabular}

Table 4 showed the relationship between the methods of treatment for NNJ and their outcome. Out of a total of 199 neonates with jaundice, 95(47.79\%) had phototherapy alone with an improved outcome of $88(48.9 \%)$.

TABLE 4:Treatment modality and their outcomes in 199 diagnosed Neonatal Jaundised.

Forms of Treatment

Phototherapy Alone

EBT Alone

Phototherapy +EBT

Phototherapy+ Chemotherapy

EBT, phototherapy+chemotherapy

Total

$\mathrm{X}^{2}=12.225, \mathrm{df}=4, \mathrm{p}=0.016$

$\begin{array}{cc}\text { Improved } & \text { Died } \\ 88(48.9) & 7(36.8) \\ 0(0.0) & 1(5.2) \\ 12(6.7) & 3(15.8) \\ 51(28.8) & 6(3.2) \\ 28(15.6) & 2(1.0) \\ 180(30) & 19(70)\end{array}$

19(70)

$\begin{array}{cc}\text { Total } & \text { Survival Rate }(\%) \\ 95(47.7) & 93 \\ 1(0.5) & 0 \\ 15(7.5) & 80 \\ 58(29.2) & 88 \\ 30(15.1) & 93 \\ 199(100) & 91\end{array}$

\section{Discussion}

Neonatal jaundice is a very common condition worldwide, occurring in up to $60 \%$ of term and $80 \%$ of preterm new born in the first week of life ${ }^{[1,2]}$. In this study a total of 664 neonates were admitted into the special care baby unit of the Pediatrics department, NDUTH during the period of this review out of which 199(17.9\%) of the neonates were diagnosed with jaundice with a yearly prevalence of 240,227, 300 per 1000 neonates admitted in the hospital for 2010,2011 and 2012 respectively making a total of all neonatal admissions in SCBU throughout this period. The highest cases of admission in SCBU on account of NNJ were seen in 2012.

The occurrence of neonatal jaundice of $25.56 \%$ of SCBU admissions observed in this study goes to confirm NNJ as among leading causes of neonatal morbidity as noted even in previous reports in Nigeria and other parts of the world, ranging between 10 to $35 \%$ of neonatal admissions ${ }^{1,25,6,7}$. Majority of which were aged between 1-2 days making about 82 (41.2\%) of the neonates admitted for NNJ. This is in support of other studies which showed that NNJ is common among neonates in the first week of life ${ }^{1,2}$. Similarly, the study revealed that NNJ occur in $56.8 \%$ of term and $40.7 \%$ of pre-term newborn. The result is closely related to other studies which showed that NNJ occurs in $60 \%$ of newborn, while the occurrence of NNJ in preterm neonates is not in consonant with other studies ${ }^{[1,2]}$. The etiological risk factors associated with neonatal jaundice were male sex,maternal age, maternal educational status, birth weight, maternal booking status, neonatal sepsis, gestational age, Apgar score, breastfeeding, tribe and use of naphthalene balls. The leading aetiological risk factors for NNJ IN NDUTH are the male sex(60.8\%), maternal education, neonatal sepsis(59.8\%), low birth weight(52.8\%). Onyearugha et al in a retrospective study conducted in South East Nigeria, to determine the occurrence, aetiological, and other associated risk factors of neonatal jaundice, it was discovered that the leading aetiological factors of neonatal jaundice in that study were septiceamia (32.5\%), and prematurity $(17.5 \%)^{8}$.

So also, G6PD deficiency, ABO incompatibility and low birth weight were found to be major predisposing /aetiologic factor in a study done between June 2009 and June 2010 at the Central Hospital Warri, 
Delta State, south-south, Nigeria as the predisposing factors of neonatal jaundice ${ }^{8}$ However in this study G6PD deficiency, and ABO incompatibility were not known to be identifiable risk factors in patients in with NNJ in NDUTH.Especially with the limitation for investigating G-6-PD deficiency for poor resource setting in this region of the world .

The male sex as the leading risk factor and has a statistical association for NNJ which is seen in $60.8 \%$ of neonates with jaundice. This is similar to other studies which show a higher prevalence among males ${ }^{8,9}$.

There is an association between maternal education and the occurrence of NNJ. The study showed a higher prevalence occurring among mothers with non-formal (66.7\% of NNJ cases ) education.

Neonatal sepsis is seen as the third leading cause of NNJ in NDUTH.It accounts for a total of $59.8 \%$ ,which is 119 out of 199.Though neonatal sepsis not the first leading cause of NNJ in this study,however,it is in agreement with other studies relating neonatal sepsis as a major risk factor for jaundice ${ }^{7,10.11}$.

Low birth weight was a major risk factor associated with NNJ in this study. 105 neonates with low birth weight were admitted for NNJ out of 199 neonates which for 52.8\% of total admission for neonatal jaundice. Other studies have reported that low birth weight is a major risk factor for pathological jaundice ${ }^{6,8,12}$.

Significantly, a good number of the neonates $40.2 \%$, with NNJ were exclusively breastfed, while 40.7\% mixed feeding, $19.1 \%$ not breast fed. In this study there is an association between breast feeding and NNJ. These observation has been previously reported in other studies ${ }^{4,7}$.

There is association between APGAR score and NNJ. The result showed a corresponding increase in the occurrence of NNJ as the APGAR score decreases: Out of the 199 NNJ cases ,good score was in $16(8.0 \%$ ), mild in $49(24.6 \%)$, moderate in $57(28.7 \%)$,severe in $77(38.7 \%)$. The highest occurrence was seen in neonates with ssevere birth asphyxia(severe APGAR score). Therefore the worst degree of birth asphyxia has higher risk for Neonatal Jaundice (NNJ). The study reveals that no association exists between use of naphthalene balls and NNJ. Only 5(2.5\%) out of 199 neonates admitted on account of jaundice had a positive history of the use of naphthalene balls.

Various treatment modalities were used as well as different outcomes were observed. These are phototherapy alone, phototherapy and exchange blood transfusion, phototherapy and chemotherapy, exchange blood transfusion and phototherapy and chemotherapy.

Out of the 199 neonates admitted as a case of NNJ. The outcome of treatment using the above listed modalities was good in 180 neonates while 19 died. See table 4 The findings in this study shows that there is a better outcome in neonates treated with a combination of more than one modalities especially for severe NNJ .This is in consonance with a study which showed a $96 \%$ survival rates in neonates treated for NNJ with all three modalities $^{13 .}$

\section{Conclusion:}

Neonatal jaundice remains high among cases admitted into the special care baby unit in developing nations.some of the risk factors are modifiable and can be changed through maternal education, early and comprehensive antenatal care as well as specialized neonatal care. Therefore antenatal and neonatal care should be improved and supported by all health care stakeholders if childhood millennium development goals would be achieved.

\section{References}

[1] Haque KM, Rahman M. (2000) an unusual case of ABO-hemolytic disease of the newborn. Bangledish Med. Res. Council. Bull; 16 (3): 105-108

[2] Wang M., Hays T., Ambruso AR, Silliman CC. Dickey WC (2005). Haemolytic disease of the Newborn cause by a high titre antigroup B $1 \mathrm{gG}$ from a Group A mother.Paediatr. Blood cancer 45(6):861-862

[3] Slusher TM, Angyo IA, Bode-Thomas F, McLaren DW, Wang RJ (2009): Transcutaneous bilirubin measurement and serum total bilirubin levels in indigineous African infants. Paediatrics 113(6): 1636-1644.4)

[4] Olusanya B.O.,Akande A.A.,Emokpae A. OloweS.A.; Tropical medicine \& international health;2009,vol.14,pp 301-310.

[5] Sarici S.U Sedar MA, Korkmz A. (2004): an early (sixth-hour) serum bilirubin assessment is useful in predicting the development of significant hyperbilirubinaemia in near terms newborns and term. Padiatrics, 113:775-780

[6] Azubuike and Nkanginieme. $2^{\text {nd }}$ edition, Textbook :Paediatrics and Child health in a Tropical region. pp 204-210.

[7] Onyearuaghe C.N.,Onyire B.N.,UgbonnaAA;NeonatalJaundice:prevalence and associated factors as seen in Federal Medical Center Abakaliki,SouthEasternNigerian;Journal of Clinical medicine and Research,march;2011,vol. 3(3) pp 40-45.

[8] HelenE.Chime,Joseph A. Egeinde: prevalence of neonatal jaundice in central hospital warri,Deltastate:International Journal of Health Research,

[9] Mohammed I.,Armeer M., Mohammed H. et al; prevalence of Rhesus type and ABO incompatibility in jaundiced neonates;JPMI 220,Vol. 225; number 0033.

[10] TiosecoJaaly,MilnerJ,Patel K et al;impact of gender on neonatal hyperbilirubinaemia: mal pediatrcrit med.2005 mar;6(2):17

[11] Eneh A.U., Oruamabo R.S. : The incidence, related factors, management and outcome of neonatal jaundice among inborn and outborn babies seen at the University of Port Harcourt Teaching Hospital;PHMJ,vol2(2)2008:pp110-117.

[12] Roland C. Ibekwe, Marry Ann U.,Vivian U.M :outcome of EBT done for Neonatal jaundice in

[13] Abakaliki,South Eastern Nigeria.Journal of Clinical neonatology,2012; vol 1;issue 1,pp 34-37

[14] LAD Duru; Features of neonatal jaundice at Irrua Specialist Hospital, Irrua, in Edo state, Nigeria;

[15] Journal of Medical Laboratory Sciences;2004;vol. 13(1);36-40. 